\title{
APORTE DE SERAPILHEIRA E NUTRIENTES EM UMA FLORESTA ESTACIONAL DECIDUAL NA REGIÃO CENTRAL DO RIO GRANDE DO SUL
}

\author{
LITTER AND NUTRIENT INPUT IN SEASONAL FOREST IN THE CENTRAL REGION OF RIO \\ GRANDE DO SUL STATE
}

\author{
Mauro Valdir Schumacher ${ }^{1}$ Denise Andréia Szymczak ${ }^{2}$ Peter Trüby $^{3}$ Eduardo Kneipp Londero ${ }^{4}$ \\ Joseane Marafiga $^{5}$
}

\section{RESUMO}

O objetivo deste estudo foi quantificar a deposição e o aporte de nutrientes através da serapilheira em um fragmento de Floresta Estacional Decidual, em Itaara, Rio Grande do Sul. Foram demarcadas seis parcelas, alocadas no interior da floresta de forma sistemática, nestas foram instalados cinco coletores de serapilheira com formato cônico. O material depositado nessa estrutura foi separado em folhas, identificadas por espécies, galhos finos (diâmetro $<0,5 \mathrm{~cm}$ ) e miscelânea (flores, frutos, sementes e restos vegetais). Após o fracionamento e separação foi realizada a determinação dos teores de nutrientes. A quantidade total de serapilheira aportada no período em estudo foi de $39,8 \mathrm{Mg} \mathrm{ha}^{-1}$, sendo composta por $68,4 \%$ de folhas, $16,3 \%$ de galhos e $15,3 \%$ de miscelânea. A espécie com maior quantidade de serapilheira depositada foi a Parapiptadenia rigida com 16,1\%, seguido de 9,0\% de Ocotea pulchella e 5,9\% de Matayba elaeagnoides. A deposição de serapilheira segue a ordem: primavera $>$ outono $>$ inverno $>$ verão. A quantidade aportada de nutrientes seguiu a ordem: $\mathrm{N}>\mathrm{Ca}>\mathrm{K}>\mathrm{Mg}>\mathrm{S}>\mathrm{P}$ para os macronutrientes, e $\mathrm{Fe}>\mathrm{Mn}>\mathrm{B}>\mathrm{Zn}>\mathrm{Cu}$ para os micronutrientes. A maior devolução de nutrientes via serapilheira foi produzida pela espécie Parapiptadenia rigida, seguida de Ocotea pulchella e Matayba elaeagnoides.

Palavras-chave: ciclagem de nutrientes; espécies nativas; sazonalidade; Mata Atlântica.

\section{ABSTRACT}

The objective of this study was to quantify the deposition and nutrients input by litter in the fragment of Seasonal Deciduous Forest, in Itaara, Rio Grande do Sul state, Brazil. Thirty circular metal collectors were allocated in six plots. The deposited material in this structure was separated in leaves, identified by species, fine branches (diameter $<0.5 \mathrm{~cm}$ ) and miscellany (flowers, fruits, seeds and plants residues). After the fractionation and separation procedures, the determination of nutrients was realized. The total amount of litter biomass input in the period of study was $39.8 \mathrm{Mg} \mathrm{ha}^{-1}$, composed $68.4 \%$ of leaves, $16.3 \%$ of branches e $15.3 \%$ of miscellany. The species with higher litter deposition was Parapiptadenia rigida with $16.1 \%$, following of $9.0 \%$ of Ocotea pulchella and $5.9 \%$ of Matayba elaeagnoides. Litter deposition follows the order: spring $>$ autumn $>$ winter $>$ summer. The nutrients input follow the order: $\mathrm{N}>\mathrm{Ca}>\mathrm{K}>\mathrm{Mg}>\mathrm{S}>\mathrm{P}$ (macronutrients) and $\mathrm{Fe}>\mathrm{Mn}>\mathrm{B}>\mathrm{Zn}>\mathrm{Cu}$ (micronutrients). The higher nutrient depositions by litter was

1 Engenheiro Florestal, Dr., Professor do Departamento de Ciências Florestais, Centro de Ciências Rurais, Universidade Federal de Santa Maria, Av. Roraima, 1000, CEP 97105-900, Santa Maria (RS), Brasil. mvschumacher@gmail.com

2 Engenheira Florestal, ${ }^{\mathrm{a}}$., professora do Departamento de Engenharia Ambiental, Universidade Tecnológica Federal do Paraná (UTFPR), campus Francisco Beltrão, Linha Santa Bárbara s/n, CEP 85.601-970 - Caixa Postal: 135, Francisco Beltrão (PR), Brasil. denisea@utfpr.edu.br

3 Engenheiro Florestal, Dr., Professor da Albert-Ludwigs-Universität Freiburg, Bertoldstr. 17, 79085 Freiburg, Alemanha.peter.trueby@bodenkunde.uni-freiburg.de

4 Engenheiro Florestal, MSc., Rua Coriolano Coelho de Souza, 55, Bairro Timbaúva, CEP 95780-000, Montenegro (RS),Brasil. eklondero@gmail.com

5 Engenheira Florestal, Rua Cuiabá, 185, Pinheiro Machado, CEP 97030-160, Santa Maria (RS), Brasil. josemarafiga@yahoo.com.br

Recebido para publicação em 18/12/2011 e aceito em 8/03/2017

Ci. Fl., v. 28, n. 2, abr. - jun., 2018 
Parapiptadenia rigida, following of Ocotea pulchella and Matayba elaeagnoides.

Keywords: nutrients cycling; native species; seasonality; Atlantic Forest.

\section{INTRODUÇÃO}

A Floresta Estacional Decidual é um ecossistema do bioma Mata Atlântica, observada em grandes altitudes e baixas temperaturas. Caracteriza-se por marcante sazonalidade pluviométrica, cuja estação seca é a mais prolongada (VELOSO; GOES FILHO, 1982). Essa tipologia florestal é conhecida por apresentar perda superior a $50 \%$ das folhas do estrato superior durante o período de inverno. No Rio Grande do Sul, ocupa uma área de $11.762,4 \mathrm{~km}^{2}$, que representa $4,2 \%$ da superfície do estado e $23,8 \%$ da área total coberta com florestas naturais (RIO GRANDE DO SUL, 2002). Além disso, é considerada uma das formações florestais mais importantes do estado, pela sua localização geográfica, área ocupada e histórico cultural (KÖNIG et al., 2002).

Sobre a camada superficial do solo, o material recém-caído dessa floresta, consistindo-se sobretudo de folhas, fragmentos de casca, galhos, flores, frutos e outras partes, é denominado de serapilheira (KOEHLER; REISSMANN; KOEHLER, 1987). A sua deposição interliga-se com vários fatores bióticos e abióticos e dependendo das características de cada ecossistema um fator pode ser mais determinante que outro. Dessa forma, tipo de vegetação, altitude, latitude, precipitação, temperatura, regimes de luminosidade, relevo, deciduosidade, estágio sucessional, disponibilidade hídrica e características do solo devem ser levados em consideração nos estudos sobre ciclagem de nutrientes via deposição de serapilheira (FIGUEIREDO FILHO et al., 2003).

A ciclagem de nutrientes em ecossistemas florestais é de suma importância para a estabilidade das florestas, uma vez que a queda da serapilheira, decomposição e liberação dos nutrientes constituintes desse tecido vegetal, retornam para o solo e posteriormente, em grande parte, à planta. No planejamento do uso de espécies nativas para a recuperação de ecossistemas degradados ou mesmo para a produção de madeiras nobres, a ciclagem de nutrientes é um dos principais aspectos a serem estudados (SCHUMACHER et al., 2004).

Segundo Carpanezzi (1997), a produção de folhas e os teores dos nutrientes presente nelas são os principais fatores que determinam a quantidade de nutrientes da serapilheira que chega ao piso florestal e ambos são influenciados por vários fatores, tanto bióticos como abióticos.

Neste contexto, o conhecimento sobre as variações de aporte de serapilheira e a ciclagem de nutrientes, é vital em ecossistemas naturais, pois é ferramenta no manejo, conservação e recuperação de fragmentos florestais remanescentes. O presente trabalho objetivou quantificar a deposição e o aporte de nutrientes através da serapilheira em um fragmento de Floresta Estacional Decidual, em Itaara, Rio Grande do Sul, Brasil.

\section{MATERIAIS E MÉTODOS}

\section{Caracterização da área de estudo}

O presente estudo foi realizado no município de Itaara, região central do Rio Grande do Sul, situado a 29॰31'39" de latitude Sul e 5346'14" de longitude Oeste, em altitude de 425 metros em relação ao nível do mar. Segundo a classificação climática de Maluf (2000), a região possui clima tipo subtemperado úmido, caracterizada pela ocorrência de chuvas durante todos os meses do ano, com temperatura média do mês mais frio inferior a $13^{\circ} \mathrm{C}$ e a temperatura média anual variando de $18,1^{\circ} \mathrm{C} \mathrm{a} 22^{\circ} \mathrm{C}$. O solo é do tipo Neossolo Litólico Eutrófico típico, com textura média, relevo forte ondulado e substrato basáltico, apresentando uma sequência de horizontes $\mathrm{A} / \mathrm{R}$. Os teores de matéria orgânica são médios, o fósforo disponível é baixo e o pH é ácido (SOCIEDADE BRASILEIRA DE CIÊNCIA DO SOLO, 2004). O solo é bastante raso, com profundidade média em torno de $35 \mathrm{~cm}$. Na Tabela 1 estão apresentadas as características químicas do solo da área de estudo 
TABELA 1: Características químicas do solo sob Floresta Estacional Decidual em Itaara-RS.

TABLE 1: Soil chemical characteristics Seasonal Deciduous Forest in Itaara, RS state.

\begin{tabular}{|c|c|c|c|c|c|c|c|c|c|c|}
\hline \multirow{2}{*}{$\begin{array}{l}\text { Prof. } \\
(\mathrm{cm})\end{array}$} & Arg. & M.O. & \multirow{2}{*}{$\begin{array}{c}\mathrm{pH} \\
\left(\mathrm{H}_{2} \mathrm{O}\right)\end{array}$} & $\mathrm{CTC}_{\text {eft }}$ & $\mathrm{Al}$ & $\mathrm{Ca}$ & $\mathrm{Mg}$ & $\mathrm{H}+\mathrm{Al}$ & \multicolumn{2}{|c|}{ Sat. (\%) } \\
\hline & \multicolumn{2}{|c|}{$\mathrm{g} \mathrm{kg}^{-1}$} & & & & $\mathrm{ol}_{\mathrm{c}} \mathrm{dm}$ & & & Bases & $\mathrm{Al}$ \\
\hline $0-10$ & 135 & 51 & 5,5 & 7,1 & 0,0 & 4,8 & 2,0 & 4,6 & 59,0 & 0,0 \\
\hline $10-20$ & 183 & 31 & 5,5 & 7,0 & 0,2 & 4,7 & 2,0 & 5,2 & 54,7 & 2,3 \\
\hline \multirow{2}{*}{$\begin{array}{l}\text { Prof. } \\
(\mathrm{cm})\end{array}$} & $\mathrm{K}$ & \multicolumn{2}{|c|}{$\mathrm{P}$} & $\mathrm{Zn}$ & $\mathrm{Cu}$ & $\mathrm{S}$ & B & $\mathrm{Fe}$ & & $\mathrm{Mn}$ \\
\hline & \multicolumn{10}{|c|}{$\mathrm{mg} \mathrm{dm}^{-3}$} \\
\hline $0-10$ & 143,0 & & & 4,3 & 0,1 & 13,5 & 0,7 & 9,3 & & 73,6 \\
\hline $10-20$ & 50,7 & & & 1,1 & 0,2 & 11,3 & 0,7 & 16,3 & & 42,7 \\
\hline
\end{tabular}

Em que: Arg. - Argila; M.O - Matéria Orgânica; $\mathrm{CTC}_{\text {eft }}-$ Capacidade de troca de cátions ao pH natural do solo; $\mathrm{Al}$ - Alumínio; Ca - Cálcio; Mg - Magnésio; H+Al - Acidez Pontencial; Sat. (\%) - Saturação de bases e de alumínio.

Em estudo anterior nessa área, Longhi e Greff (2006), considerando os valores de Índice de Importância Relativa, observaram principalmente espécies da família Fabaceae, Euphorbiaceae e Sapindaceae. Em contrapartida, a família com maior número de representantes foi Myrtaceae (12 espécies), sendo todos eles com baixos valores nos índices relativos (frequência relativa). Ainda, segundo esses autores, na floresta em estudo, foram encontradas com maior frequência, as espécies arbóreas: Allophylus edulis, Caliandra tweediei, Cupania vernalis, Dalbergia frutescens, Eugenia hiemalis, Helietta apiculata, Lithraea brasiliensis, Lithraea molleoides, Luehea divaricata, Matayba eleagnoides, Nectandra megapotamica, Ocotea puberula, Ocotea pulchella, Parapiptadenia rigida, Cordia americana, Quillaja brasiliensis, Sebastiana brasiliensis e Sebastiania commersoniana, entre outras.

Ainda, segundo esses autores, a Parapiptadenia rigida apresenta o maior valor de dominância relativa $14,56 \%$ além de ter o maior índice de valor de importância $24,39 \%$. A floresta apresenta um índice de diversidade específica de Shanon-Wiener (H') de 3,32. Este valor é considerado alto, ou seja, a floresta apresenta alta diversidade, porém, isso não quer dizer que seja rica em espécies, os indivíduos podem estar bem distribuídos entre as espécies encontradas na floresta.

\section{Metodologia}

Foram demarcadas seis parcelas de formato retangular, medindo $25 \times 17 \mathrm{~m}$ cada, alocadas no interior da floresta de forma sistemática, conforme especificações de Péllico Netto e Brena (1997), e em cada uma das parcelas foram instalados cinco coletores metálicos cônicos com $0,50 \mathrm{~m}$ de diâmetro, a um metro do solo. Nesta estrutura metálica foi fixada tela tipo sombrite (malha 2,0 mm), com $30 \mathrm{~cm}$ de profundidade. Mensalmente entre os anos de 2003 a 2008 foi realizada a coleta do material depositado nos coletores.

Em laboratório, todo o material foi separado nas frações folhas, galhos finos (diâmetro $<0,5 \mathrm{~cm}$ ) e miscelânea (flores, frutos, sementes e restos vegetais não identificáveis). Além disso, a fração folhas foi separada em nível de espécie de maior densidade (ocorrência na floresta) e de possível identificação como o angico-vermelho (Parapiptadenia rigida), aroeira (Lithraea molleoides) camboatá-branco (Matayba elaeagnoides), camboatá-vermelho (Cupania vernalis), canela-guaicá (Ocotea puberula), canela-lageana (Ocotea pulchella), canela-preta (Nectandra megapotamica), em nível de família para as Fabaceae, e as demais foram classificadas como "outros".

Após o procedimento de fracionamento e separação, cada amostra foi posta a secar em estufa de circulação e renovação de ar a uma temperatura de $70^{\circ} \mathrm{C}$ por aproximadamente 72 horas. Posteriormente, procedeu-se a pesagem em balança digital de precisão 0,01g para a determinação do peso seco. Em conseguinte, as amostras foram moídas em moinho tipo Wiley com peneira de 30 mesh, para posterior determinação dos teores dos nutrientes seguindo a metodologia de Tedesco et al. (1995).

A partir do produto da massa seca de serapilheira, depositada nos coletores e dos teores de nutrientes nela contidos, estimou-se a transferência de nutrientes ao piso florestal, em relação à cada fração estudada. 


\section{RESULTADOS E DISCUSSÃO}

\section{Deposição de serapilheira}

A deposição total de serapilheira no período de estudo, (Tabela 2), foi de $39,8 \mathrm{Mg} \mathrm{ha}^{-1}$. Com o passar dos anos, a deposição de serapilheira decresceu. No ano de 2003, a biomassa de serapilheira foi 8,1 $\mathrm{Mg} \mathrm{ha}^{-1}$ chegando a 5,8 Mg ha- em 2008. Esta redução pode ser atribuída à perturbação sofrida pela floresta decorrente de animais (principalmente bovinos) que circulavam na área. $\mathrm{O}$ pastejo e pisoteio estariam interferindo negativamente na regeneração e recomposição da floresta. Vestígios de queimada indicam que essa prática também possa estar desfavorecendo o processo de sucessão e consequentemente a redução no aporte de serapilheira.

A serapilheira depositada é composta por $68,4 \%$ de folhas, $15,3 \%$ de miscelânea, $16,3 \%$ de galhos finos, corroborando Bray e Ghoran (1964) quando afirmam que as folhas normalmente constituem 60 a $80 \%$ da biomassa de serapilheira que cai sobre o solo. A média de deposição de serapilheira foi de $6,6 \mathrm{Mg}$ $\mathrm{ha}^{-1}$ ano $^{-1}$, abaixo dos valores encontrados por outros autores nesse mesmo ecossistema. König et al. (2002) estudaram fragmentos florestais de Floresta Estacional Decidual em Santa Maria-RS, e encontraram uma deposição de 9,2 $\mathrm{Mg} \mathrm{ha}^{-1}$ ano $^{-1}$. Os últimos autores observaram ainda uma formação de $67,8 \%$ de folhas, $19,3 \%$ por galhos finos ( $<1 \mathrm{~cm}$ de diâmetro) e 12,9\% de miscelânea para a serapilheira depositada.

Os dados do estudo de König et al. (2002) foram obtidos nos anos de 1999 e 2000 e os autores descreveram que a floresta já estava sofrendo perturbações humanas e de animais. Esse fato fortalece a premissa de que a deposição de serapilheira tende a decrescer anualmente impulsionada por perturbações externas a ela. Em 1999/2000, a deposição média anual era de 9,2 $\mathrm{Mg} \mathrm{ha}^{-1}$ ano $^{-1}$, em 2003 passou a 8,1 Mg ha $^{-1}$ ano $^{-1}$, em 2004 foi de 6,6 $\mathrm{Mg} \mathrm{ha}^{-1}$ ano $^{-1} \mathrm{e}$, finalmente, em 2008, a deposição foi de 5,8 $\mathrm{Mg} \mathrm{ha}^{-1}$ ano $^{-1}$.

Entre as espécies arbóreas identificadas, Parapiptadenia rigida, Ocotea pulchella e Matayba elaeagnoides correspondem juntas a $31 \%$ do total de serapilheira depositada no piso florestal, já a Cupania vernalis representou 2,1\%, o menor valor no grupo em questão. A primeira apresentou a maior média de deposição foliar 1.068,9 $\mathrm{kg} \mathrm{ha}^{-1}$ ano $^{-1}$ (Tabela 2). Cunha (1997) afirma que as espécies mais importantes na deposição de folhedo são as de maior dominância e densidade, sendo isto aplicável no presente estudo para Parapiptadenia rigida, Ocotea pulchella e Matayba elaeagnoides. Florestas dominadas por poucas espécies, como a Floresta Estacional Decidual, na região central do Rio Grande do Sul, têm sua deposição de serapilheira controlada pela fenologia dessas poucas espécies que, portanto, possuem um papel decisivo no equilíbrio destes ecossistemas.

TABELA 2: Aporte anual de serapilheira $\left(\mathrm{kg} \mathrm{ha}^{-1}\right)$ em uma Floresta Estacional Decidual na região central do Rio Grande do Sul, Brasil.

TABLE 2: Annual input of litter $\left(\mathrm{kg} \mathrm{ha}^{-1}\right)$ in the Seasonal Deciduous Forest in central region of Rio Grande do Sul state, Brazil.

\begin{tabular}{|c|c|c|c|c|c|c|c|c|}
\hline \multirow{2}{*}{ Fração } & \multicolumn{6}{|c|}{ Ano } & \multirow{2}{*}{ Média } & \multirow{2}{*}{ Total } \\
\hline & 2003 & 2004 & 2005 & 2006 & 2007 & 2008 & & \\
\hline 1 & $\begin{array}{c}1.158,5 \\
(14,3)\end{array}$ & $\begin{array}{c}1.249,0 \\
(19,0)\end{array}$ & $\begin{array}{c}1.064,7 \\
(14,4)\end{array}$ & $\begin{array}{l}967,4 \\
(15,4)\end{array}$ & $\begin{array}{c}1.058,6 \\
(18,7)\end{array}$ & $\begin{array}{l}915,6 \\
(15,8)\end{array}$ & $1.068,9$ & $\begin{array}{c}6.413,8 \\
(16,1)\end{array}$ \\
\hline 2 & $\begin{array}{c}229,6 \\
(2,8)\end{array}$ & $\begin{array}{c}190,2 \\
(2,9)\end{array}$ & $\begin{array}{c}193,7 \\
(2,6)\end{array}$ & $\begin{array}{l}150,3 \\
(2,4)\end{array}$ & $\begin{array}{l}142,8 \\
(2,5)\end{array}$ & $\begin{array}{c}213,7 \\
(3,7)\end{array}$ & 186,7 & $\begin{array}{c}1.120,3 \\
(2,8)\end{array}$ \\
\hline 3 & $\begin{array}{c}562,5 \\
(6,9)\end{array}$ & $\begin{array}{c}308,8 \\
(4,7)\end{array}$ & $\begin{array}{c}603,1 \\
(8,1)\end{array}$ & $\begin{array}{c}386,6 \\
(6,1)\end{array}$ & $\begin{array}{c}195,0 \\
(3,4)\end{array}$ & $\begin{array}{c}277,9 \\
(4,8)\end{array}$ & 389,0 & $\begin{array}{c}2.334,0 \\
(5,9)\end{array}$ \\
\hline 4 & $\begin{array}{l}169,2 \\
(2,1)\end{array}$ & $\begin{array}{l}70,4 \\
(1,1)\end{array}$ & $\begin{array}{l}157,7 \\
(2,1)\end{array}$ & $\begin{array}{l}117,2 \\
(1,9)\end{array}$ & $\begin{array}{l}121,8 \\
(2,2)\end{array}$ & $\begin{array}{c}211,9 \\
(3,7)\end{array}$ & 141,4 & $\begin{array}{c}848,3 \\
(2,1)\end{array}$ \\
\hline 5 & $\begin{array}{c}383,6 \\
(4,7)\end{array}$ & $\begin{array}{c}303,7 \\
(4,6)\end{array}$ & $\begin{array}{c}362,2 \\
(4,9)\end{array}$ & $\begin{array}{l}182,3 \\
(2,9)\end{array}$ & $\begin{array}{l}195,5 \\
(3,5)\end{array}$ & $\begin{array}{c}259,2 \\
(4,5)\end{array}$ & 281,1 & $\begin{array}{c}1.686,5 \\
(4,2)\end{array}$ \\
\hline 6 & $\begin{array}{l}953,8 \\
(11,8)\end{array}$ & $\begin{array}{c}330,8 \\
(5,0)\end{array}$ & $\begin{array}{l}871,3 \\
(11,8)\end{array}$ & $\begin{array}{c}528,2 \\
(8,4)\end{array}$ & $\begin{array}{c}360,8 \\
(6,4)\end{array}$ & $\begin{array}{c}557,5 \\
(9,6)\end{array}$ & 600,4 & $\begin{array}{c}3.602,3 \\
(9,0)\end{array}$ \\
\hline 7 & $\begin{array}{c}387,5 \\
(4,8)\end{array}$ & $\begin{array}{c}238,0 \\
(3,6)\end{array}$ & $\begin{array}{c}225,6 \\
(3,0)\end{array}$ & $\begin{array}{l}122,7 \\
(1,9)\end{array}$ & $\begin{array}{l}139,1 \\
(2,5)\end{array}$ & $\begin{array}{c}403,5 \\
(7,0)\end{array}$ & 252,7 & $\begin{array}{c}1.516,4 \\
(3,8)\end{array}$ \\
\hline 8 & $\begin{array}{c}200,3 \\
(2,5)\end{array}$ & $\begin{array}{l}138,3 \\
(2,1)\end{array}$ & $\begin{array}{l}145,3 \\
(2,0)\end{array}$ & $\begin{array}{l}102,2 \\
(1,6)\end{array}$ & $\begin{array}{l}136,8 \\
(2,4)\end{array}$ & $\begin{array}{c}206,9 \\
(3,6)\end{array}$ & 154,9 & $\begin{array}{c}929,9 \\
(2,3)\end{array}$ \\
\hline
\end{tabular}

Continuação... 
TABELA 2: Continuação...

TABLE 2: Continued...

\begin{tabular}{|c|c|c|c|c|c|c|c|c|}
\hline \multirow{2}{*}{ Fração } & \multicolumn{6}{|c|}{ Ano } & \multirow{2}{*}{ Média } & \multirow{2}{*}{ Total } \\
\hline & 2003 & 2004 & 2005 & 2006 & 2007 & 2008 & & \\
\hline Outros & $\begin{array}{c}1.902,7 \\
(23,4)\end{array}$ & $\begin{array}{c}1.654,6 \\
(25,2)\end{array}$ & $\begin{array}{c}1.507,3 \\
(20,3)\end{array}$ & $\begin{array}{c}1.349,0 \\
(21,4)\end{array}$ & $\begin{array}{c}1.171,0 \\
(20,7)\end{array}$ & $\begin{array}{c}1.205,4 \\
(20,8)\end{array}$ & $1.465,0$ & $\begin{array}{c}8.790,1 \\
(22,1)\end{array}$ \\
\hline Total Folhas & $\begin{array}{c}5.947,8 \\
(73,3)\end{array}$ & $\begin{array}{c}4.483,8 \\
(68,4)\end{array}$ & $\begin{array}{c}5.131,0 \\
(69,2)\end{array}$ & $\begin{array}{c}3.906,0 \\
(62,0)\end{array}$ & $\begin{array}{c}3.521,5 \\
(62,1)\end{array}$ & $\begin{array}{c}4.251,7 \\
(73,3)\end{array}$ & $4.540,3$ & $\begin{array}{c}27.241,7 \\
(68,4)\end{array}$ \\
\hline Galhos & $\begin{array}{c}1.401,0 \\
(17,3)\end{array}$ & $\begin{array}{c}1.052,8 \\
(16,0)\end{array}$ & $\begin{array}{c}1.100,9 \\
(14,9)\end{array}$ & $\begin{array}{c}1.221,8 \\
(19,4)\end{array}$ & $\begin{array}{l}841,5 \\
(14,9)\end{array}$ & $\begin{array}{l}878,4 \\
(15,1)\end{array}$ & $1.082,7$ & $\begin{array}{c}6.496,4 \\
(16,3)\end{array}$ \\
\hline Miscelânea & $\begin{array}{l}765,9 \\
(9,4)\end{array}$ & $\begin{array}{c}1.026,5 \\
(15,6) \\
\end{array}$ & $\begin{array}{c}1.177,5 \\
(15,9) \\
\end{array}$ & $\begin{array}{c}1.169,0 \\
(18,6)\end{array}$ & $\begin{array}{c}1.301,2 \\
(23,0)\end{array}$ & $\begin{array}{l}671,1 \\
(11,6) \\
\end{array}$ & $1.018,5$ & $\begin{array}{c}6.111,3 \\
(15,3) \\
\end{array}$ \\
\hline Total & $\begin{array}{l}8.114,7 \\
(100,0)\end{array}$ & $\begin{array}{l}6.563,1 \\
(100,0)\end{array}$ & $\begin{array}{l}7.409,4 \\
(100,0)\end{array}$ & $\begin{array}{l}6.296,8 \\
(100,0)\end{array}$ & $\begin{array}{l}5.664,2 \\
(100,0)\end{array}$ & $\begin{array}{l}5.801,2 \\
(100,0)\end{array}$ & - & $\begin{array}{c}39.849,4 \\
(100,0)\end{array}$ \\
\hline
\end{tabular}

Em que: Fração (1 - Parapiptadenia rigida, 2 - Lithraea molleoides, 3 - Matayba elaeagnoides, 4 - Cupania vernalis, 5 - Ocotea puberula, 6 - Ocotea pulchella, 7 - Nectandra megapotamica e 8 - Família Fabaceae). Valores entre parênteses referem-se à porcentagem em relação ao total de serapilheira.

De acordo com a Figura 1 e Tabela 3, o aporte de folhas teve picos em maio (470,3 $\mathrm{kg} \mathrm{ha}^{-1}$ ano$\left.{ }^{1}\right)$ e novembro $\left(602,8 \mathrm{~kg} \mathrm{ha}^{-1}\right.$ ano $\left.^{-1}\right)$ indicando que as maiores deposições foliares ocorreram no outono, e principalmente na primavera. Para galhos finos, o pico de deposição manteve-se similar nas folhas com maior queda em novembro $\left(151,5 \mathrm{~kg} \mathrm{ha}^{-1}\right)$. A deposição de miscelânea teve pico no mês de dezembro $(179,0$ $\left.\mathrm{kg} \mathrm{ha}^{-1} \mathrm{ano}^{-1}\right)$. Dessa forma, a produção de serapilheira seguiu a ordem decrescente: primavera $>$ outono $>$ inverno $>$ verão.

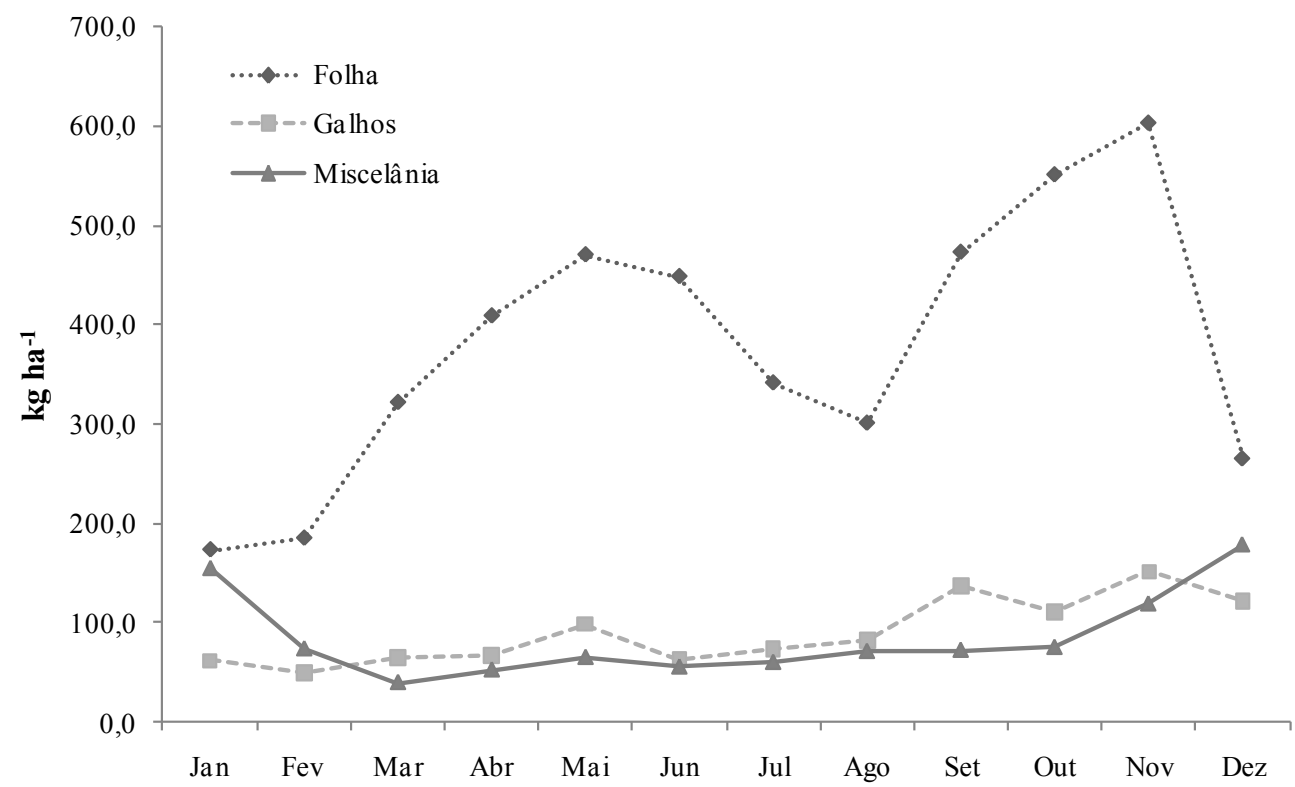

FIGURA 1: Sazonalidade da deposição $\left(\mathrm{kg} \mathrm{ha}^{-1}\right.$ ano $\left.^{-1}\right)$ de serapilheira em uma Floresta nativa do Rio Grande do Sul, Brasil, média de seis anos de estudo.

FIGURE 1: Seasonal deposition of litter $\left(\mathrm{kg} \mathrm{ha}^{-1} \mathrm{ano}^{-1}\right)$ in the Native Forest of Rio Grande do Sul state, Brazil, average of six years of study.

Britez et al. (1992) também encontraram esse padrão de distribuição de serapilheira para uma floresta de araucária no Paraná. Estes autores, explicam que a maior queda de serapilheira na primavera é devido a estas florestas situarem-se em zonas de clima subtropical, sem períodos prolongados de frio intenso nem de seca. A diversidade florística nestas regiões e a ausência de extremos climáticos permitem que a floresta produza serapilheira durante todo o ano, acentuando-se após o inverno, antes que a maioria da vegetação retome o crescimento vegetativo. 
TABELA 3: Aporte médio mensal $\left(\mathrm{kg} \mathrm{ha}^{-1}\right)$ de serapilheira por espécie em um Florestal Estacional Decidual na região central do Rio Grande do Sul, Brasil.

TABLE 3: Mean month input of litter for species $\left(\mathrm{kg} \mathrm{ha}^{-1}\right)$ in the Seasonal Deciduous Forest in central region of Rio Grande do Sul state, Brazil.

\begin{tabular}{cccccccccccccc}
\hline Fração & Jan & Fev & Mar & Abr & Mai & Jun & Jul & Ago & Set & Out & Nov & Dez & Total \\
\hline 1 & 44,6 & 39,6 & 66,2 & 112,6 & 184,9 & 210,0 & 170,1 & 76,8 & 36,0 & 25,9 & 53,7 & 48,6 & 1069,0 \\
2 & 9,7 & 13,1 & 16,5 & 12,8 & 9,7 & 6,6 & 4,7 & 7,6 & 20,5 & 24,4 & 48,7 & 12,2 & 186,7 \\
3 & 11,0 & 12,1 & 19,8 & 27,8 & 29,8 & 16,1 & 11,9 & 27,4 & 78,9 & 81,9 & 52,2 & 20,2 & 389,0 \\
4 & 4,5 & 3,9 & 17,9 & 13,3 & 11,0 & 6,9 & 5,1 & 6,8 & 17,0 & 28,2 & 20,1 & 6,6 & 141,4 \\
5 & 15,3 & 14,8 & 19,6 & 18,3 & 20,9 & 9,6 & 10,5 & 12,2 & 25,5 & 34,8 & 61,8 & 37,7 & 281,1 \\
6 & 14,9 & 19,8 & 41,2 & 26,6 & 28,8 & 22,9 & 18,5 & 30,1 & 59,9 & 102,3 & 186,7 & 48,6 & 600,4 \\
7 & 9,5 & 11,8 & 26,1 & 13,9 & 11,7 & 10,5 & 11,5 & 18,7 & 32,1 & 55,0 & 33,6 & 18,3 & 252,7 \\
8 & 12,3 & 8,6 & 15,6 & 30,0 & 28,1 & 23,4 & 12,8 & 4,8 & 6,1 & 4,0 & 4,5 & 4,8 & 155,0 \\
9 & 77,0 & 73,5 & 98,7 & 153,4 & 145,4 & 142,2 & 96,2 & 116,3 & 196,7 & 194,4 & 141,5 & 67,7 & 1502,9 \\
Total folhas & 198,8 & 197,2 & 321,6 & 408,8 & 470,3 & 448,4 & 341,2 & 300,7 & 472,8 & 550,8 & 602,8 & 264,8 & - \\
10 & 62,0 & 49,9 & 64,9 & 66,9 & 98,7 & 63,6 & 73,7 & 81,8 & 136,9 & 110,6 & 151,5 & 122,2 & 1082,7 \\
11 & 155,0 & 73,8 & 39,7 & 52,5 & 65,1 & 55,4 & 60,1 & 71,2 & 72,3 & 75,2 & 119,2 & 179,0 & 1018,6 \\
\hline Total & 415,8 & 320,9 & 426,2 & 528,2 & 634,1 & 567,4 & 475,0 & 453,7 & 682,0 & 736,6 & 873,5 & 566,0 & - \\
\hline
\end{tabular}

Em que: Fração (1 - Parapiptadenia rigida, 2 - Lithraea molleoides, 3 - Matayba elaeagnoides, 4 - Cupania vernalis, 5 - Ocotea puberula, 6 - Ocotea pulchella, 7 - Nectandra megapotamica, 8 - Família Fabaceae, 9 - Outros, 10 - Galhos finos e 11 - Miscelânea).

\section{Teores e quantidade de nutrientes}

As médias anuais de concentração dos nutrientes (Tabela 4) para as oito espécies estudadas, fração "outros", galhos finos e miscelânea no período de seis anos de estudo demonstram que Parapiptadenia rigida, quando comparada às demais espécies apresentou as maiores concentrações de N, P, Ca. Já o K, Mg e $\mathrm{S}$ tiveram maiores concentrações nas folhas de Matayba elaeagnoides, nas quais também foram observadas menores concentrações de $\mathrm{Cu}$ e Zn. A Ocotea puberula foi a espécie que apresentou a menor concentração de $\mathrm{Ca}$, enquanto a Ocotea pulchella as menores concentrações de $\mathrm{K}$ e Mg. Nectandra megapotamica teve as menores concentrações de P, Fe e Mn e a maior concentração de Zn. A família Fabaceae teve as maiores concentrações de $\mathrm{B}$ e Mn. Quanto à distribuição nos demais compartimentos, foi observado que os galhos apresentaram as menores concentrações de $\mathrm{P}$ e B e maior de $\mathrm{Cu}$. Na miscelânea foram quantificadas as menores concentrações de $\mathrm{P}$ e Fe.

As maiores concentrações de $\mathrm{N}$ no tecido foliar de Parapiptadenia rigida, pode ser explicado pelo fato dessa espécie pertencer à família Fabaceae que possui associações simbióticas de suas raízes com bactérias fixadoras de $\mathrm{N}_{2}$ atmosférico. Estudando leguminosas arbóreas em Botucatu-SP, Bertalot et al. (2004) encontraram para todas as espécies um padrão semelhante quanto aos teores de macronutrientes na serapilheira, obedecendo a seguinte ordem: $\mathrm{N}>\mathrm{Ca}>\mathrm{K}>\mathrm{Mg}>\mathrm{P}>\mathrm{S}$. Esse padrão é similar ao do presente estudo, variando apenas na maior concentração de $\mathrm{S}$ seguido de $\mathrm{P}$. Cabe aqui ressaltar que a Família Fabaceae e a Ocotea puberula também apresentam teores elevados de N, P e S.

A proporção entre os vários nutrientes na biomassa pode ser fortemente determinada pela espécie e família, pelo órgão analisado ou ainda pelo estádio de desenvolvimento da planta (LARCHER, 2000). Em alguns ecossistemas florestais, as folhas jovens tendem a apresentar maiores concentrações de $\mathrm{N}, \mathrm{P}$ e $\mathrm{K}$. À medida que as folhas envelhecem, ocorre diminuição destes nutrientes, enquanto as concentrações de $\mathrm{Ca}, \mathrm{Mg}$ e $\mathrm{Fe}$ aumentam, em função dos processos de translocação dos nutrientes e do acúmulo dos produtos fotossintéticos na folha (MARIN; MEDINA 1981). A concentração de nutrientes foliares varia de acordo com a sazonalidade, idade da folha, luz disponível, lixiviação e o tipo de solo florestal (BOEGER; WISNIEWSKI; REISSMANN, 2005).

Neves, Martins e Reissmann (2001) encontraram diferenças significativas entre as concentrações médias foliares de Mn para Virola surinamensis e Ceiba pentandra. Isto indica que as espécies possuem diferenças nas exigências deste nutriente e na capacidade de sua absorção pelas raízes. As concentrações 
de $\mathrm{Fe}$ e $\mathrm{Cu}$ corroboram o estudo de Moraes e Domingos (1997) realizado em floresta de restinga na cidade de São Paulo. Os altos teores de $\mathrm{Zn}$ observados podem estar relacionados às altas concentrações desse elemento no solo da área de estudo.

TABELA 4: Concentrações médias anuais dos nutrientes nas diferentes espécies presentes na serapilheira em uma Floresta Estacional Decidual na região central do Rio Grande do Sul, Brasil.

TABLE 4: Mean annual concentration of nutrients in different species in litter in the Seasonal Deciduous Forest in central region of Rio Grande do Sul state, Brazil.

\begin{tabular}{|c|c|c|c|c|c|c|c|c|c|c|c|}
\hline \multirow{2}{*}{ Fração } & $\mathrm{N}$ & $P$ & $\mathrm{~K}$ & $\mathrm{Ca}$ & $\mathrm{Mg}$ & $\mathrm{S}$ & $\mathrm{B}$ & $\mathrm{Cu}$ & $\mathrm{Fe}$ & $\mathrm{Mn}$ & $\mathrm{Zn}$ \\
\hline & \multicolumn{6}{|c|}{$\mathrm{g} \mathrm{kg}^{-1}$} & \multicolumn{5}{|c|}{$\mathrm{mg} \mathrm{kg}^{-1}$} \\
\hline 1 & 27,70 & 1,26 & 3,63 & 23,31 & 2,26 & 1,45 & 47,66 & 6,84 & 146,36 & 88,30 & 36,31 \\
\hline 2 & 15,14 & 0,89 & 5,13 & 18,17 & 2,58 & 1,21 & 44,34 & 10,14 & 113,53 & 114,12 & 37,28 \\
\hline 3 & 17,96 & 0,92 & 7,73 & 11,51 & 6,91 & 1,80 & 45,85 & 4,33 & 96,98 & 312,91 & 33,33 \\
\hline 4 & 19,26 & 0,90 & 5,83 & 12,93 & 4,34 & 1,70 & 37,42 & 8,33 & 114,44 & 375,59 & 47,15 \\
\hline 5 & 23,42 & 1,05 & 4,13 & 10,43 & 1,62 & 1,74 & 49,11 & 8,35 & 108,74 & 114,32 & 50,04 \\
\hline 6 & 18,16 & 0,80 & 3,26 & 11,02 & 1,54 & 1,22 & 44,07 & 7,78 & 102,27 & 171,69 & 36,62 \\
\hline 7 & 16,32 & 0,80 & 4,42 & 12,45 & 2,22 & 1,12 & 42,22 & 8,05 & 80,35 & 77,80 & 55,70 \\
\hline 8 & 23,95 & 0,88 & 6,36 & 22,26 & 4,74 & 1,44 & 71,56 & 10,05 & 136,21 & 402,09 & 41,86 \\
\hline Outros & 21,40 & 1,04 & 6,03 & 19,93 & 3,07 & 1,51 & 54,99 & 9,08 & 151,15 & 192,84 & 34,25 \\
\hline Galhos & 16,06 & 0,70 & 3,72 & 22,91 & 2,33 & 0,98 & 32,83 & 12,89 & 162,48 & 183,07 & 48,91 \\
\hline Miscelânea & 25,61 & 1,47 & 5,27 & 14,66 & 2,25 & 1,55 & 43,03 & 11,34 & 572,39 & 152,15 & 42,28 \\
\hline Média & 20,45 & 0,97 & 5,05 & 16,32 & 3,08 & 1,43 & 46,65 & 8,83 & 162,26 & 198,62 & 42,16 \\
\hline
\end{tabular}

Em que: Fração (1 - Parapiptadenia rigida, 2 - Lithraea molleoides, 3 - Matayba elaeagnoides, 4 - Cupania vernalis, 5 - Ocotea puberula, 6 - Ocotea pulchella, 7 - Nectandra megapotamica e 8 - Família Fabaceae).

A quantidade total de nutrientes (Tabela 5), foi maior na fração outros, pois esta teve a maior quantidade de folhas depositada. $\mathrm{Cu}$ e $\mathrm{Fe}$ apresentaram os maiores teores nos galhos e nos resíduos. Nas frações depositadas pela espécie de Cupania vernalis, verificaram-se as menores quantidades de nutrientes aportados, pois apresentaram a menor quantidade de folhas aportada. $\mathrm{Mn}$ e $\mathrm{Zn}$, além da menor biomassa de folhas, também obtiveram os menores teores dos respectivos nutrientes.

A ordem decrescente de aporte de macronutrientes foi: $\mathrm{N}>\mathrm{Ca}>\mathrm{K}>\mathrm{Mg}>\mathrm{S}>\mathrm{P}$. A magnitude média de aporte de nutrientes via serapilheira foi similar à observada nos estudos de Cunha et al. (1993), Cunha (1997) e Caldeira et al. (2008) em florestas nativas variando apenas a ordem de $\mathrm{Ca}>\mathrm{N}$. Este fato pode ser relacionado ao maior número de indivíduos da família Fabaceae na Floresta estudada. Porém, para Brun (2004), o aporte de nutrientes na fração folhas da floresta secundária corrobora com a ordem de acúmulo de nutrientes deste estudo.

A contínua ciclagem de nutrientes (no sistema solo-planta-solo), é de suma importância para o fragmento florestal em questão, visto que, nesse local, o solo é bastante raso (em torno de $35 \mathrm{~cm}$ de profundidade), e a ocupação radicular restringe-se à camada superficial.

Lopes et al. (2006) em estudo também realizado em Itaara, mostram que as raízes finas, predominantemente, encontram-se localizadas nos primeiros $10 \mathrm{~cm}$ de profundidade, apresentando distribuição homogênea. Os autores ainda destacam a importância das raízes finas para a absorção de água e nutrientes do solo, além destas, as raízes de diâmetro superiores assumem papel fundamental na sustentação mecânica que suporta a estrutura vertical da árvore. Isso evidencia a grande importância desempenhada pela devolução de nutrientes via decomposição da serapilheira ao solo.

Garrido e Poggiani (1981) verificaram que a deposição de nutrientes seguiu a seguinte ordem: $\mathrm{N}>\mathrm{Ca}>\mathrm{K}>\mathrm{Mg}>\mathrm{P}$ para os povoamentos de Lithraea molleoides e Parapiptadenia rigida. Os indivíduos de Parapiptadenia rigida destacaram-se pela maior deposição de $\mathrm{N}, \mathrm{P}$ e Ca, concordando com os resultados obtidos no presente estudo. 
TABELA 5: Quantidade total de nutrientes aportados via serapilheira e por espécies em uma Floresta Estacional Decidual na região central do Rio Grande do Sul, Brasil.

TABLE 5: Total amount of nutrients input by litter and for species in the Seasonal Deciduous Forest in central region of Rio Grande do Sul state, Brazil.

\begin{tabular}{|c|c|c|c|c|c|c|c|c|c|c|c|}
\hline \multirow{2}{*}{ Fração } & $\mathrm{N}$ & $\mathrm{P}$ & $\mathrm{K}$ & $\mathrm{Ca}$ & $\mathrm{Mg}$ & $\mathrm{S}$ & B & $\mathrm{Cu}$ & $\mathrm{Fe}$ & $\mathrm{Mn}$ & $\mathrm{Zn}$ \\
\hline & \multicolumn{6}{|c|}{$\mathrm{kg} \mathrm{ha}^{-1}$} & \multicolumn{5}{|c|}{$\mathrm{g} \mathrm{ha}^{-1}$} \\
\hline \multirow{2}{*}{1} & 176,4 & 8,1 & 20,5 & 159,2 & 13,7 & 9,6 & 330,8 & 47,0 & 933,4 & 545,8 & 214,1 \\
\hline & $(20,8)$ & $(19,3)$ & $(10,6)$ & $(21,2)$ & $(12,4)$ & $(17,1)$ & $(17,5)$ & $(12,7)$ & $(12,4)$ & $(7,8)$ & $(13,8)$ \\
\hline \multirow{2}{*}{2} & 17,1 & 1,0 & 6,1 & 20,9 & 3,0 & 1,4 & 51,8 & 11,3 & 132,9 & 127,6 & 37,4 \\
\hline & $(2,0)$ & $(2,4)$ & $(3,2)$ & $(2,8)$ & $(2,7)$ & $(2,4)$ & $(2,7)$ & $(3,1)$ & $(1,8)$ & $(1,8)$ & $(2,4)$ \\
\hline \multirow{2}{*}{3} & 41,3 & 2,1 & 18,7 & 27,0 & 17,1 & 4,2 & 109,9 & 9,9 & 233,6 & 771,2 & 73,9 \\
\hline & $(4,9)$ & $(5,0)$ & $(9,6)$ & $(3,6)$ & $(15,4)$ & $(7,5)$ & $(5,8)$ & $(2,7)$ & $(3,1)$ & $(11,0)$ & $(4,8)$ \\
\hline \multirow{2}{*}{4} & 16,2 & 0,8 & 5,7 & 11,2 & 3,9 & 1,4 & 32,6 & 7,1 & 104,6 & 335,7 & 42,5 \\
\hline & $(1,9)$ & $(1,9)$ & $(3,0)$ & $(1,5)$ & $(3,5)$ & $(2,5)$ & $(1,7)$ & $(1,9)$ & $(1,4)$ & $(4,8)$ & $(2,7)$ \\
\hline \multirow{2}{*}{5} & 39,0 & 1,8 & 7,2 & 19,6 & 2,7 & 3,0 & 87,9 & 14,0 & 194,8 & 200,7 & 79,8 \\
\hline & $(4,6)$ & $(4,4)$ & $(3,7)$ & $(2,6)$ & $(2,5)$ & $(5,3)$ & $(4,6)$ & $(3,8)$ & $(2,6)$ & $(2,9)$ & $(5,2)$ \\
\hline \multirow{2}{*}{6} & 62,4 & 2,9 & 11,5 & 42,8 & 5,4 & 4,3 & 167,5 & 28,3 & 387,9 & 644,5 & 126,1 \\
\hline & $(7,4)$ & $(7,0)$ & $(5,9)$ & $(5,7)$ & $(4,9)$ & $(7,6)$ & $(8,9)$ & $(7,6)$ & $(5,2)$ & $(9,2)$ & $(8,1)$ \\
\hline \multirow{2}{*}{7} & 25,2 & 1,3 & 6,7 & 20,9 & 3,5 & 1,8 & 65,3 & 12,0 & 130,8 & 121,1 & 79,0 \\
\hline & $(3,0)$ & $(3,0)$ & $(3,5)$ & $(2,8)$ & $(3,2)$ & $(3,2)$ & $(3,5)$ & $(3,2)$ & $(1,7)$ & $(1,7)$ & $(5,1)$ \\
\hline \multirow{2}{*}{8} & 21,6 & 0,9 & 5,4 & 23,7 & 4,8 & 1,4 & 77,1 & 9,6 & 134,7 & 435,3 & 40,1 \\
\hline & $(2,5)$ & $(2,1)$ & $(2,8)$ & $(3,1)$ & $(4,3)$ & $(2,5)$ & $(4,1)$ & $(2,6)$ & $(1,8)$ & $(6,2)$ & $(2,6)$ \\
\hline \multirow{2}{*}{ Outros } & 188,3 & 9,4 & 54,0 & 185,1 & 27,9 & 13,6 & 511,5 & 79,6 & $1.364,3$ & $1.761,9$ & 309,4 \\
\hline & $(22,2)$ & $(22,5)$ & $(27,9)$ & $(24,6)$ & $(25,2)$ & $(24,3)$ & $(27,0)$ & $(21,5)$ & $(18,1)$ & $(25,2)$ & $(20,0)$ \\
\hline \multirow{2}{*}{ Galhos } & 103,0 & 4,4 & 23,5 & 157,7 & 15,0 & 6,2 & 208,0 & 82,9 & $1.009,6$ & $1.157,4$ & 306,3 \\
\hline & $(12,1)$ & $(10,7)$ & $(12,1)$ & $(21,0)$ & $(13,5)$ & $(11,0)$ & $(11,0)$ & $(22,4)$ & $(13,4)$ & $(16,6)$ & $(19,8)$ \\
\hline \multirow[t]{2}{*}{ Resíduos } & 158,0 & 9,1 & 34,5 & 83,7 & 13,8 & 9,3 & 248,5 & 69,0 & $2.894,0$ & 884,6 & 239,2 \\
\hline & $(18,6)$ & $(21,7)$ & $(17,8)$ & $(11,1)$ & $(12,4)$ & $(16,5)$ & $(13,1)$ & $(18,6)$ & $(38,5)$ & $(12,7)$ & $(15,5)$ \\
\hline \multirow{2}{*}{ Total } & 848,6 & 41,7 & 193,8 & 751,7 & 111,0 & 56,2 & $1.890,8$ & 370,8 & $7.520,7$ & $6.985,8$ & $1.547,8$ \\
\hline & $100,0)$ & 00,0 & $(100,0)$ & $(100,0)$ & 00,0 & $100,0)$ & $, 0)$ & $(100,0)$ & $0,0)$ & $(100,0)$ & $(100,0)$ \\
\hline
\end{tabular}

Em que: Fração (1 - Parapiptadenia rigida, 2 - Lithraea molleoides, 3 - Matayba elaeagnoides, 4 - Cupania vernalis, 5 - Ocotea puberula, 6 - Ocotea pulchella, 7 - Nectandra megapotamica e 8 - Família Fabaceae). Valores entre parênteses referem-se a porcentagem em relação ao total de serapilheira.

Dentre as espécies identificadas, Parapiptadenia rigida, Ocotea pulchella e Matayba elaeagnoides aportaram as maiores quantidades de macronutrientes, sendo que Parapiptadenia rigida se sobressaiu às demais para todos os macronutrientes analisados, exceto no Mg. Cupania vernalis e a Lithraea molleoides foram as espécies que aportaram as menores quantidades de nutrientes. Ocotea puberula e a Nectandra megapotamica ficam em uma faixa intermediária em relação à quantidade de nutrientes devolvidas ao solo.

Parapiptadenia rigida aportou $20,8 \%$ de N, seguido da Ocotea pulchella que representou $16,5 \%$ do aporte total deste nutriente. A primeira também correspondeu a $21,2 \%$ da quantidade de Ca aportada e Matayba elaeagnoides representou 3,6\% do total de $\mathrm{Mg}$, entre as espécies identificadas. Parapiptadenia rigida e Ocotea pulchella corresponderam juntas a $26,4 \%$ da quantidade total de B devolvido ao solo; $20,3 \%$ de $\mathrm{Cu} ; 17,6 \%$ de $\mathrm{Fe}$ e $21,9 \%$ de $\mathrm{Zn}$, sendo que a Parapiptadenia rigida foi a que mais contribui para essa percentagem. Matayba elaeagnoides e Ocotea pulchella corresponderam juntas a 20,2\% do aporte total de Mn.

\section{CONCLUSÕES}

A quantidade de serapilheira aportada foi diminuindo gradativamente na escala de tempo observada, indicando que perturbações externas estão interferindo negativamente na estrutura da floresta.

$\mathrm{O}$ acúmulo de serapilheira ao longo de todo o período foi de $39,8 \mathrm{Mg} \mathrm{ha}^{-1}$, composto por $68,4 \%$ de folhas, $16,3 \%$ de galhos e $15,3 \%$ de miscelânea. A espécie com maior quantidade de serapilheira 
depositada foi Parapiptadenia rigida com 16,1\%, seguida de 9,0\% de Ocotea pulchella e 5,9\% de Matayba elaeagnoides. A primavera foi a estação do ano responsável pela maior deposição de serapilheira.

A quantidade aporta de nutrientes seguiu a seguinte ordem: $\mathrm{N}>\mathrm{Ca}>\mathrm{K}>\mathrm{Mg}>\mathrm{S}>\mathrm{P}$ para os macronutrientes e $\mathrm{Fe}>\mathrm{Mn}>\mathrm{B}>\mathrm{Zn}>\mathrm{Cu}$ para os micronutrientes. A maior devolução de nutrientes via serapilheira foi produzida pela espécie Parapiptadenia rigida, seguida de Ocotea pulchella e Matayba elaeagnoides.

\section{AGRADECIMENTOS}

À Fundação Brigada Militar através do CETRAPAe a Universidade de Freiburg através do convênio PROBRAL (Convênio Brasil-Alemanha).

\section{REFERÊNCIAS}

BERTALOT, M. J. A. et al. Retorno de nutrientes ao solo via deposição de serapilheira de quatro espécies leguminosas arbóreas na região de Botucatu - São Paulo, Brasil. Scientia Forestalis, Piracicaba, n. 65, p. 219-227, jun. 2004.

BOEGER, M. R. T.; WISNIEWSKI, C.; REISSMANN, C. B. Nutrientes foliares de espécies arbóreas de três estádios Sucessionais de floresta Ombrófila densa no sul do Brasil. Acta Botanica Brasilica, São Paulo, v. 19, p. 167-181, 2005.

BRAY, J. R.; GHORAN, E. Litter production in forest of the world. Londres: Advances in Ecological Research, 1964.

BRITEZ, R. M. et al. Deposição estacional de serapilheira e macronutrientes em uma floresta de Araucária, São Mateus do Sul, Paraná. Revista do Instituto Florestal, São Paulo, v. 4, n. 3, p. 766-772, 1992.

BRUN, E. J. Biomassa na Floresta Estacional Decidual de Santa Tereza, RS. 2004. 152 f. Dissertação (Mestrado em Engenharia Florestal) - Programa de Pós-graduação em Engenharia Florestal, Universidade Federal de Santa Maria, Santa Maria, 2004.

CALDEIRA, M. V. W. et al. Quantificação de serapilheira e de nutrientes em uma Floresta Ombrófila Densa. Revista do Setor de Ciências Agrárias, Londrina, v. 29, n. 1, p. 53-68, 2008.

CARPANEZZI, A. A. Banco de sementes e deposição de folhedo e seus nutrientes em povoamentos de bracatinga (Minosa scabrella Bentham) na Região Metropolitana de Curitiba-PR. 1997. $177 \mathrm{f}$. Tese (Doutorado em Ciências Biológicas) - Universidade Estadual Paulista, Rio Claro, 1997.

CUNHA, G. C. Aspectos da ciclagem de nutrientes em diferentes fases sucessionais de uma Floresta Estacional do Rio Grande do Sul. 1997. 86 f. Dissertação (Mestrado em Engenharia Florestal) - Escola Superior de Agricultura "Luiz de Queiroz", Piracicaba, 1997.

CUNHA, G. C. et al. Dinâmica nutricional em Floresta Estacional Decidual com ênfase aos minerais provenientes da deposição da serapilheira. Ciência Florestal, Santa Maria, v. 3, n. 1, p. 35-64, 1993.

FIGUEIREDO FILHO, A. et al. Avaliação estacional da deposição de serapilheira em uma floresta ombrófila mista localizada no sul do Estado do Paraná. Ciência Florestal, Santa Maria, v. 13, p. 11-18, 2003.

GARRIDO, M. A. O.; POGGIANI, F. Avaliação da quantidade e do conteúdo de nutrientes do folhedo de alguns povoamentos puros e misto de espécies indígenas. Silvicultura de São Paulo, v. 15/16, p. 1-22, 1981.

KOEHLER, C. W.; REISSMANN, C. B.; KOEHLER, H. S. Deposição de resíduos orgânicos (serapilheira) e nutrientes em plantio de Araucaria angustifolia em função do sítio. Revista do Setor de Ciências Agrárias, Londrina, v. 9, n. 1, p. 89-94, 1987.

KÖNIG, F. G. et al. Avaliação da sazonalidade da produção de serapilheira numa floresta Estacional Decidual no município de Santa Maria-RS. Revista Árvore, Viçosa, MG, v. 26, n. 1, p. 429-435, 2002.

LARCHER, W. Ecofisiologia vegetal. São Carlos: Rima, 2000. 531 p.

LONGHI, S. J.; GREFF, L. T. B. Distribuição de espécies arbóreas em relação a parâmetros ambientais em uma Floresta Estacional Decidual no município de Itaara, RS. 2006. 16 f. Relatório (Iniciação Científica) - CNPq/Pibic, Brasília, 2006. 16 p.

LOPES, V. G. et al. Quantificação da biomassa de raízes de uma floresta estacional decidual na região de 
Itaara - RS - Brasil. In: JORNADAS TÉCNICAS FORESTALES Y AMBIENTALES, 12., 2006, Eldorado. Anais... Eldorado: INTA, 2006.

MALUF, J. R. T. Nova classificação climática do Estado do Rio Grande do Sul. Revista Brasileira de Agrometeorologia, Santa Maria, v. 8, n. 1, p. 141-150, 2000.

MARIN, D.; MEDINA, E. Duracion foliar, contenido de nutrientes y esclerofilia en arboles de un bosque muy seco tropical. Acta Cientifica Venezolana, Caracas, v. 32, p. 508-514, 1981.

MORAES, R. M.; DOMINGOS, M. Elementos minerais em folhas de espécies arbóreas de Mata Atlântica e Mata de Restinga, na Ilha do Cardoso, SP. Revista Brasileira de Botânica, São Paulo, v. 20, n. 2, p. 133-138, 1997.

NEVES, E. J. M.; MARTINS, E. G.; REISSMANN, C. B. Deposição de serapilheira e de nutrientes de duas espécies da Amazônia. Boletim de Pesquisa Florestal, Colombo, v. 43, p. 47-60, 2001.

PÉLLICO NETTO, S.; BRENA, D. A. Inventário florestal. Santa Maria: UFSM; CEPEF, 1997.

RIO GRANDE DO SUL. Secretaria Estadual do Meio Ambiente. Inventário florestal contínuo do Rio Grande do Sul. Porto Alegre: FATEC; SEMA, 2002. Disponível em: <www.ufsm.br/ifcrs>. Acesso em: 20 maio 2004.

SCHUMACHER, M. V. et al. Produção de serapilheira em uma floresta de Araucaria angustifolia (Bertol) Kuntze no município de Pinhal Grande-RS. Revista Árvore, Viçosa, MG, v. 28, p. 29-37, 2004.

SOCIEDADE BRASILEIRA DE CIÊNCIA DO SOLO. Comissão de Química e Fertilidade do Solo. Manual de adubação e calagem para os Estados do Rio Grande do Sul e de Santa Catarina. 10. ed. Porto Alegre: SBCS, 2004. 400 p.

TEDESCO, M. J. et al. Análise de solo, plantas e outros materiais. Porto Alegre: UFRGS, 1995. 174 p. (Boletim Técnico, n. 5).

VELOSO, H. P.; GOES FILHO, L. Fitogeografia brasileira, classificação fisionômica ecológica da vegetação Neotropical. Salvador: Projeto RADAMBRASIL, 1982. (Boletim Técnico). 